\title{
USING A VECTOR SWOT - ANALYSIS TO DETERMINE THE GUIDELINES FOR THE TRAINING OF TRACKED VEHICLES DRIVER IN THE BULGARIAN ARMY
}

\author{
Rosen PETKOV, Ilian BANKATEV \\ "Vasil Levski”" National Military University, Veliko Tarnovo, Bulgaria \\ rosen_st_petkov@abv.bg, idbankatev@nvu.bg
}

\begin{abstract}
In the process of making strategic decisions and defining trends in process development, SWOT analysis is particularly important as a reliable prognosis tool. The results of the situational analysis allow to identify priorities and objectives on the one hand and to assist in the selection of development guidelines on the other. The purpose of the following report is to optimize the process of training the tracked vehicles driver in the Bulgarian Army by defining an indicated vector in a SWOT quadrant and identifying development strategies.
\end{abstract}

Keywords: SWOT - analysis, training, tracked vehicles driver, situation model, indicated vector.

\section{Introduction}

Choosing a strategic solution and choosing a development strategy is an extremely important component in the management activity of any corporation or institution, especially in the contemporary conditions of dynamic development of social processes, technologies and needs, in a highly competitive environment, globalization and transfer of production, financial, material and information resources. An appropriate strategic choice based on a reliable prognosis is the only true condition and a guarantee for successful development in response to new challenges. Not only state, union, corporate, military, but all other institutions, such as educational, informational, public, nowadays need clear missions, goals, priorities and strategic directions for their future existence and prosperity.
In order to delineate realistic and precise strategic direction for the development of the organization (process), a wide variety of approaches and models have been developed. Analyzing nearly 1,500 articles, Henry Mintsberg [1] formally identifies ten basic schools, supporting and developing concepts and methods for formulating strategies - from those who direct, teach, prescribe, pretend to be guides in how to form the strategy on the one hand, to those who seek to explain how the strategy is actually devised in practice, or to considering the strategy as a process, as something nondermined, which is formed by time and circumstances, and can include analysis, reflection, policy, planning, vision or intuition and any other possible strategic choice, depending on the time and context. The first group of schools includes, as Mintzberg calls them "Big Model Strategy," the most common view of the process of 
forming a strategy that is mostly associated with the Harvard Business School; "Strategy as a plan," with its most influential representative, Igor Ansof, and "strategy as a position" from Sun Tzu to the Boston Matrix and Michael Porter's models, which sets out to describe "what strategies best fit concrete and all circumstances' [1]. The belief that strategy is the result of a conscious and meticulous thought process is predominant. Current goals and objectives are reviewed in the light of SWOT analysis (Strengths, Weaknesses / Opportunities and Threats / threats) and then strategic alternatives are identified. Subsequently, these alternatives are evaluated in different aspects and the strategic choice is made (Figure 1).

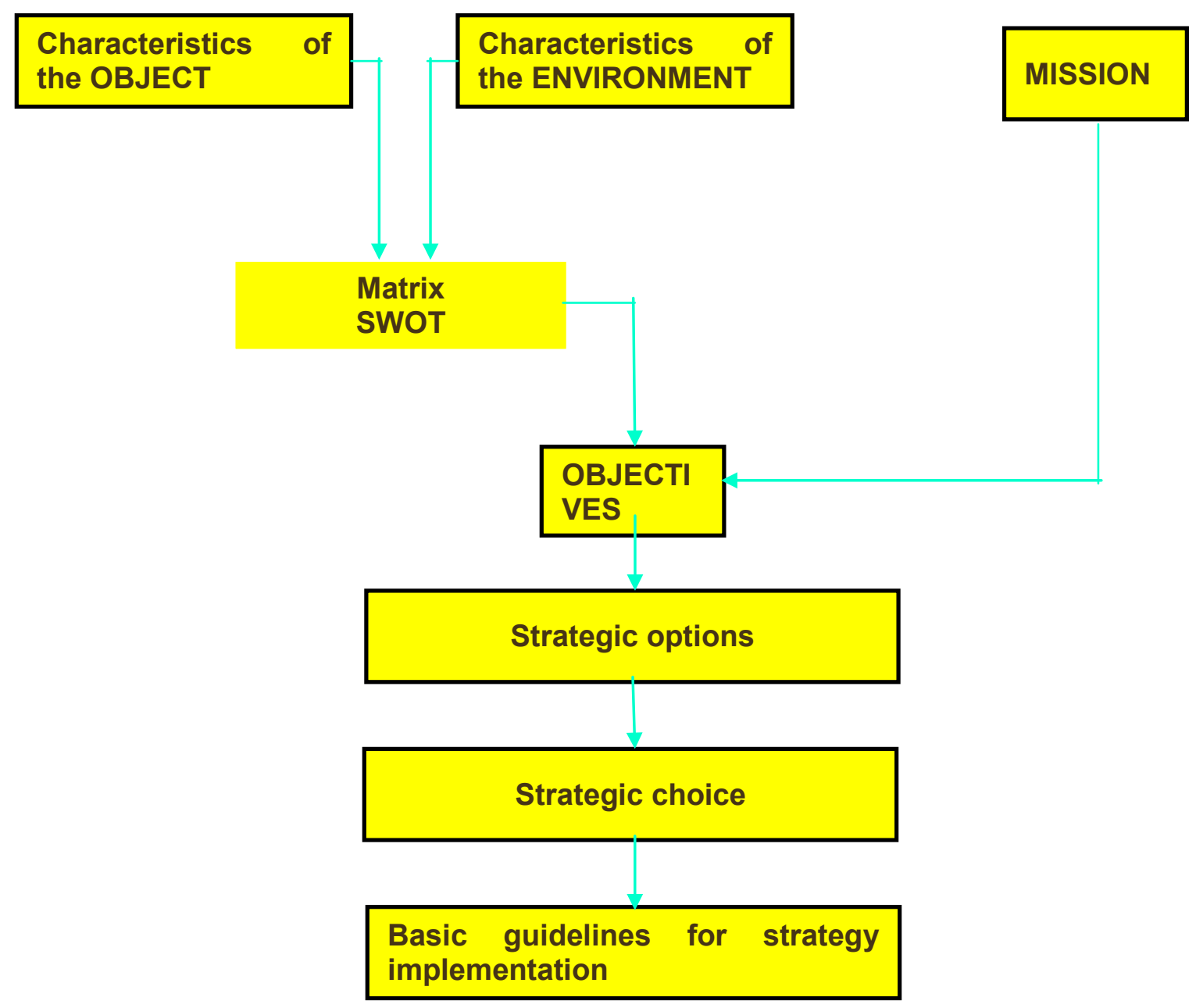

Figure 1: Key elements of the strategic decision process

A key point in the process of the strategic decision is the SWOT analysis. Its purpose is to evaluate the external conditions (favorable opportunities - threats) and the internal conditions (strengths - weaknesses) of the process or organization. The results of situational analysis make it possible to specify and clearly identify the priorities and objectives on the one hand and to assist in choosing a strategy - on the other. It also has to answer the following questions [2]: 1. What are the inhibitions and constraints that make the organization or process vulnerable, and make them less effective and reduce their results? 
2. What are the imbalances in the organization (the corporation, the firm) or the process?

3. What are the threats and how they can be used as opportunities?

4. Why are the organization or processes vulnerable to external and business circumstances?

As far as the expected results of the SWOT analysis are sufficiently specific, it is necessary to carry it out as accurately and precisely as possible and to conclude with clear and unambiguous conclusions and recommendations.

The implementation of the method of strategic analysis, however, is not a sufficiently adopted practice, in Bulgaria as well as in other countries. Critics of the SWOT analysis point out, as a flaw in the method, mainly the practical difficulties in its realization, the large number of combinations between the elements in the lists of internal and external focus, different and even controversial interpretation of the established relationships, and hence the positioning of variants and compilation of profiles for strategic alternatives. Indisputable in this respect is K. Bowman's statement: "Unfortunately, the SWOT analysis in inept hands leads to the creation of a long list of recommendations, and the longer that list is, the more misty the emerging strategic picture will be." In conclusion, the author [3] gives the following recommendation: "While the nature of the applied strategic management models, and in particular the SWOT analysis, is not sufficiently understood by the practitioners, I would recommend that they be used at the interim stage of the study - to deepen the analysis of the state of the enterprise, and then rely on our intuition or in a nutshell, restrict the use of these models only to generate our own new strategic ideas and that's it. " However, since the appearance of Alfred Chandler and his fundamental work "Strategy and Structure" (1962), strategic management as a category and as a factual application has started more and more urgently to need to develop its methods and techniques for methodological research and to list all possible changes in the main variables of both the environment and the enterprise, and also to make a complete list of possible alternatives for resolving the strategic issue. " [4] Obviously, there is a need to develop models that support strategic decisionmaking and, above all, to improve the techniques for their practical application.

\section{The purpose of study}

The purpose of this paper is to optimize the strategic decision-making process by defining a specified vector in the quadrants of the SWOT space of the strategic options and applying it the determining of the main directions and perspectives in the process and the organization of the training of specialists - mechanic guides-for the Bulgarian Army in the long run.

The usual practice $[4,5,6,7]$ is to reveal the strengths and weaknesses of the organization and the external factors favorable opportunities and threats, to position the elements of the inner focus with those of the external focus in tabular or graphic form, thus forming the so-called swot-matrix or state matrix. There are four areas (quadrants) of possible states: strengths - opportunities, strengths - threats, weaknesses - opportunities and weaknesses - threats. These four zones form the space of strategic options. The possible strategic decisions are analyzed in each of the zones individually and the winning strategies are (intuitively, heuristically) determined - the strategic portfolio that is.

\section{The results of vector SWOT analysis}

In this paper, it is proposed to go further in the development of the SWOT analysis. Quantify the strengths, weaknesses, opportunities and threats by quantitative measures (grades' estimates and weight ratios, probability characteristics, etc.). For each group an integral quantitative indicator (or individual elements to be considered in possible combining schemes) can be 
calculated and the results plotted on the axis of a rectangular coordinate system - the linked points form a coordinate frame in the space of the strategic options, and the connecting vectors from the beginning of the coordinate system to the top of the frame will be state vectors. The magnitude and direction (angle to the coordinate axes) of each state vector in its quadrant will be the quantitative indicators that characterize the situation in which the process or organization is based on the criteria being studied. The more the state vector is greater in absolute value, the more clearly the corresponding situation is expressed, and the bigger the angle between the vector and one of the axes, the less the influence of the factors of this axis on the overall state of the studied institution. The vector state of the first quadrant - between the "strengths" axes - "opportunities" will characterize the importance of offensive strategies, the vector in the second quadrant (weaknesses opportunities) the strategies of reorientation, the third quadrant (weaknesses - threats) in IV quadrant (strengths - threats) - defensive strategies.

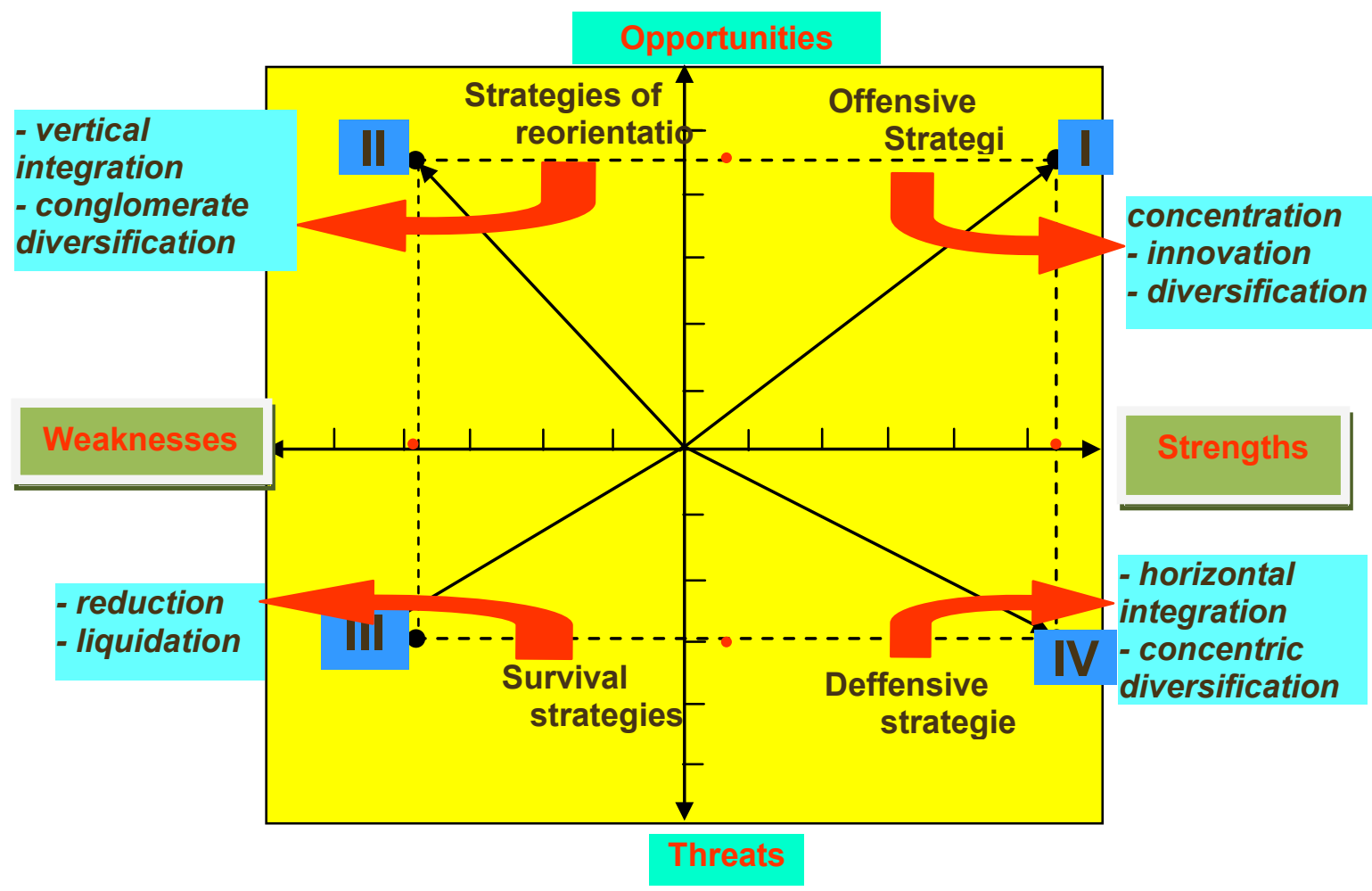

Figure 2: Coordinate model of strategic options

The coordinate status model offers a new opportunity to reduce the matrix SWOT analysis to a more determinate method with the expectation of a more definite and concrete result.

Since the state vectors differentially reflect the different sides of the relationship between the individual elements (or group of elements) in the plane of the internal and external focus of a single system under study, the idea arises to look for an integral indicator to summarize or broaden the situational aspect of the process / organization. Such an integral metric, corresponding to the nature of the analysis, may be the vector sum of situational vectors from each quadrant - the vector that closes a broken line from the addition vectors.

In Fig. 3 is the result of the vector SWOT analysis where the vectors F1, F2, F3 and 
F4 are the state vectors for the respective directions. quadrant taken with their magnitudes and

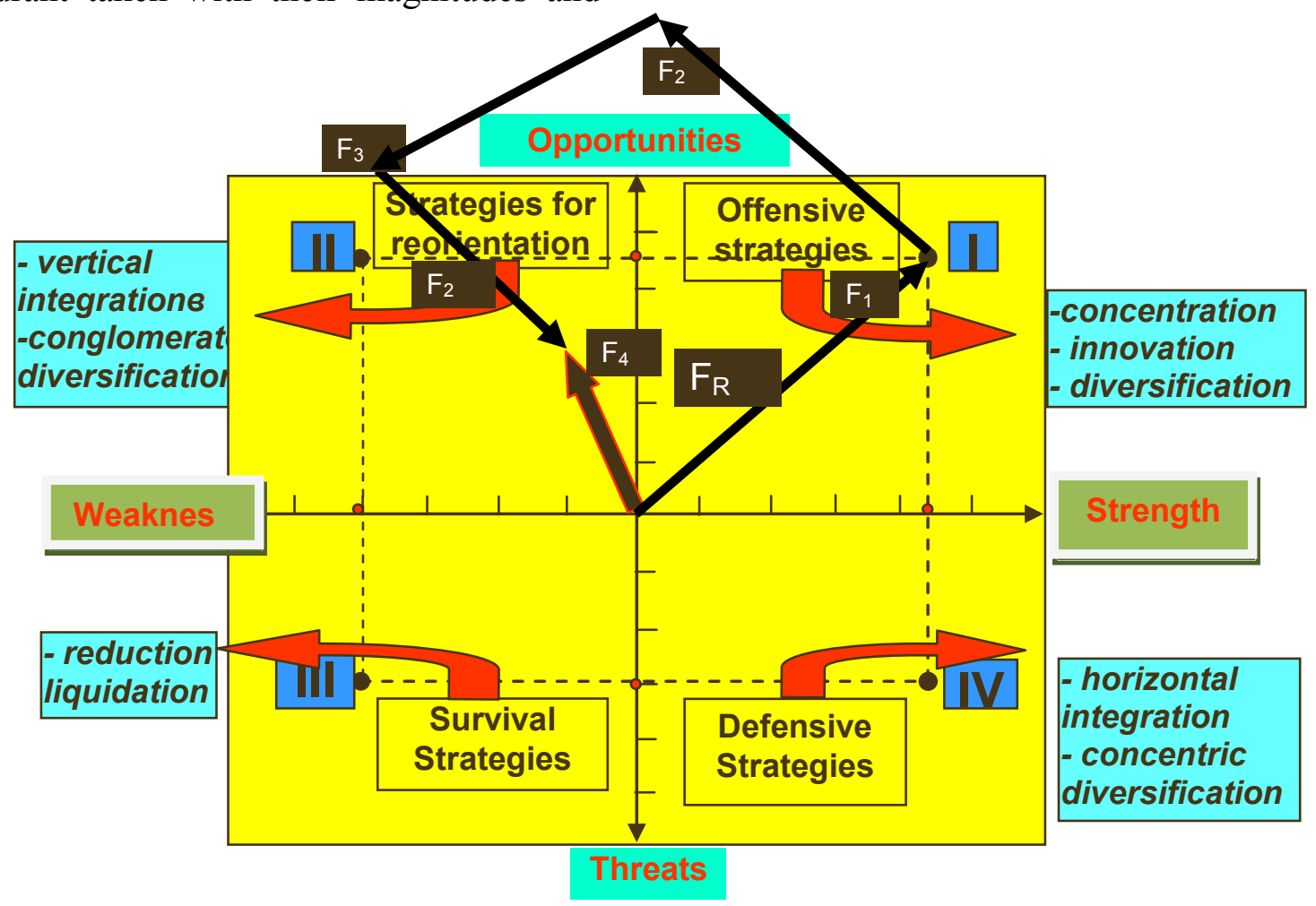

Figure 3: Vector SWOT-analysis

The sum of the vectors F1, F2, F3 and F4 is the resulting directional vector $F R$, defining the strategic direction of the choice. FR = F1 + F2 + F3 + F4

Dependence (1), designed on the axes of a Cartesian coordinate system, is actually an algebraic system of linear equations whose analytical solution determines the coordinates of the directional vector.

The analytical interpretation of the vector SWOT analysis provides prerequisites for simulation and computer modeling of the process and allows a detailed and in-depth study of internal characteristics and their correlation with external conditions in order to formulate adequate and reliable prognoses and strategic alternatives as well as to define the main direction for development. Above mentioned options can be better achieved in the light of the dynamic SWOT analysis. The development of coordinate and vector models of situational analysis at different time points will produce results that will accurately reflect rapidly changing environmental conditions and outline the strategic planning horizon [5] for which the priorities and main goals of the process are set, and the organization of the training of specialists in the Bulgarian Army.

The "vector SWOT analysis" method converts the "complex, difficult procedure for evaluating often qualitative, complex and interacting factors" [5], which is the situation analysis, in a precise and reliable, computer-based program for a comprehensive study of the state of process and predicting its development.

The concrete results of the conducted SWOT analysis in the process of training specialists for the Bulgarian Army show (Figure 3) that appropriate approaches for a new organization of training are: vertical integration - united resources (instructors, training materials, methodological approaches, finance etc.), combined stages 
of selection, training and realization for the whole Bulgarian Army on the one hand and conglomerate diversification on the other introduction of completely new technologies in training (simulators / trainers, etc.), diversification of the goals of the training for specific activities and operations resulting from the new missions and tasks to the Bulgarian Army.

\section{Conclusions}

Finally, the shared view [1] that the strategy exists as a formula and not a "unique view" should be highlighted. It contains the potential for developing creativity and completing intuition with specific data, but it often leads to the development of emulation strategies. In the opinion of Professor H. Mintzberg, the mistake lies in the fact that the analysis replaces the strategy instead of fulfilling its main function - to support the process of developing an adequate solution.

[1] Mintzberg, H. Strategy in Companies, http://www.v-ratio.ru and http://www.clif.ru/management/strategy/plan/10 school.shtml

[2] DRAKAR, P. Effective management. "Classic and Style" Publishing House, Sofia, 2002.

[3] TOKAREV, C. Application of the SWOT analysis in company strategies, on materials from the site http://www.clif.ru/management/strategy/plan/adapt_swot.shtml.

[4] TARRAGO, F and others. Strategic Management. University Publishing House "Holding", Sofia, 1999.

[5] STOYANOV, E. Strategic marketing. University Publishing House "Holding", Sofia, 1999.

[6] PANAYOTOV, D and others. Strategic planning (theory methodology, case studies). Economic Academy "D. A. Tsenov ", Svishtov, 2001.

[7] BLAGOEV, C. Marketing. International University, Sofia, 2003. 